\title{
Epidemiological Observations on the Association Between Anosmia and COVID-19 Infection: Analysis of Data From a Self-Assessment Web Application
}

Fabrice Denis ${ }^{1}, \mathrm{MD}, \mathrm{PhD}$; Simon Galmiche ${ }^{2}, \mathrm{MD}$; Aurélien Dinh $^{3}, \mathrm{MD}$; Arnaud Fontanet ${ }^{2}, \mathrm{MD}, \mathrm{PhD}$; Arnaud Scherpereel $^{4}$, MD, PhD; Francois Benezit ${ }^{5}, \mathrm{MD}$; François-Xavier Lescure ${ }^{6,7}, \mathrm{MD}, \mathrm{PhD}$

\footnotetext{
${ }^{1}$ Inter-regional Cancer Institut Jean Bernard, Le Mans, France

${ }^{2}$ Emerging Diseases Epidemiology Unit, Institut Pasteur, Paris, France

${ }^{3}$ Service de maladies infectieuses et tropicales, Hôpital Raymond Poincaré, Assistance Publique - Hôpitaux de Paris, Garches, France

${ }^{4}$ Service de pneumologie, Centre Hospitalier Régional Universitaire de Lille, Lille, France

${ }^{5}$ Service de maladies infectieuses et réanimation médicale, Centre Hospitalier Universitaire de Rennes Pointchaillou, Rennes, France

${ }^{6}$ Infectious and Tropical Diseases Department, Bichat-Claude Bernard University Hospital and University of Paris, Assistance Publique - Hôpitaux de Paris, Paris, France

${ }^{7}$ Team DesCID, Infection, Antimicrobials, Modelling, Evolution - U1137, French Institute for Health and Medical Research, Institut national de la santé et de la recherche médicale, Paris, France
}

\section{Corresponding Author:}

Fabrice Denis, MD, PhD

Inter-regional Cancer Institut Jean Bernard

9 , rue Beauverger

Le Mans, 72100

France

Phone: 33243475810

Email: f.denis@cjb72.org

\section{Abstract}

Background: We developed a self-assessment and participatory surveillance web application for coronavirus disease (COVID-19), which was launched in France in March 2020.

Objective: Our objective was to determine if self-reported symptoms could help monitor the dynamics of the COVID-19 outbreak in France.

Methods: Users were asked questions about underlying conditions, sociodemographic status, zip code, and COVID-19 symptoms. Depending on the symptoms reported and the presence of coexisting disorders, users were told to either stay at home, contact a general practitioner (GP), or call an emergency phone number. Data regarding COVID-19-related hospitalizations were retrieved from the Ministry of Health.

Results: As of March 29, 2020, the application was opened 4,126,789 times; 3,799,535 electronic questionnaires were filled out; and 2,477,174 users had at least one symptom. In total, $34.8 \%(\mathrm{n}=1,322,361)$ reported no symptoms. The remaining users were directed to self-monitoring ( $\mathrm{n}=858,878,22.6 \%)$, GP visit or teleconsultation $(\mathrm{n}=1,033,922,27.2 \%)$, or an emergency phone call $(n=584,374,15.4 \%)$. Emergency warning signs were reported by $39.1 \%$ of participants with anosmia, a loss of the sense of smell $(n=127,586)$ versus $22.7 \%$ of participants without anosmia $(n=1,597,289)$. Anosmia and fever and/or cough were correlated with hospitalizations for COVID-19 (Spearman correlation coefficients=0.87 and 0.82 , respectively; $P<.001$ for both).

Conclusions: This study suggests that anosmia may be strongly associated with COVID-19 and its severity. Despite a lack of medical assessment and virological confirmation, self-checking application data could be a relevant tool to monitor outbreak trends.

Trial Registration: ClinicalTrials.gov NCT04331171; https://clinicaltrials.gov/ct2/show/NCT04331171

(J Med Internet Res 2020;22(6):e19855) doi: 10.2196/19855 


\section{KEYWORDS}

COVID-19; anosmia; epidemiological surveillance; self-assessment; web application; outbreak; symptoms; self-assessment; surveillance; epidemiology

\section{Introduction}

Web-based self-reporting of symptoms is a growing field and has been used to improve survival in oncology [1,2]; it can be used as a participatory surveillance tool for coronavirus disease (COVID-19) or other influenza-like illnesses as well [3,4]. We thought of applying the same technology to optimize patient triage for COVID-19 patients in France and alleviate the burden on emergency call centers. A self-assessment and participatory surveillance website [5] was developed and launched during the growing phase of the COVID-19 epidemic in France in March 2020. Our objective was to determine if self-reported symptoms could help monitor outbreak dynamics in France. We report here the analysis of the first 13 days of web application usage.

\section{Methods}

Users were recruited via national media campaigns in France, including social media, radio, and magazine campaigns, between March 17-29, 2020. Participants were recruited through the maladiecoronavirus.fr website [5]. Respondents provided information on sociodemographic data, zip code, and coexisting disorders anonymously. They were asked about nine symptoms associated with possible COVID-19 infection-fever (body temperature $>37.7^{\circ} \mathrm{C}$ ), unusual cough, shortness of breath, sore throat, muscle aches, diarrhea, anorexia, and asthenia. Anosmia, a loss of the sense of smell, was added on March 21, 2020. Following symptom reporting, a notification was sent, recommending the user either to stay at home and use the website again in case of evolving symptomatology (self-monitoring), or to contact a general practitioner (GP), or to call an emergency number if they reported dyspnea or anorexia. A questionnaire was built according to Chinese reports and French experience [6]. The website was not considered a medical device by regulatory authorities since no tracking was performed and data were anonymous. We compared the distribution of web-based, self-reported symptoms to that of hospitalized COVID-19 patients according to Ministry of Health reports. Spearman correlation coefficients were used for statistical analysis.

\section{Results}

Between March 17-29, 2020, the website was accessed 4,126,789 times; 3,799,535 electronic questionnaires were filled out; and 2,477,174 users had at least one out of the nine symptoms included in the questionnaire (Figure 1). In total, $1,322,361(34.8 \%)$ participants reported no symptoms. The remaining patients (median age 37 years; range 15-99 years) were directed to self-monitoring $(858,878,22.6 \%)$, GP visit or teleconsultation $(1,033,922,27.2 \%)$, or an emergency phone call $(584,374,15.4 \%)$.

Of all symptomatic patients, anosmia was reported by $17.1 \%$ $(325,910 / 1,903,741)$, fever was reported by $33.5 \%$ $(828,952 / 2,477,174)$, and cough by $61.2 \%$ $(1,515,557 / 2,477,174)$. Emergency warning signs (dyspnea or complete anorexia) were reported by $39.1 \%$ of participants with anosmia $(n=127,586)$ versus $22.7 \%$ of participants without anosmia ( $\mathrm{n}=1,597,289 ; P<.001$; Table 1$)$. Anosmia and fever and/or cough were correlated with COVID-19-related hospitalizations (Spearman correlation coefficients $=0.87$ and 0.82 , respectively; $P<.001$ for both; Figure 2). 
Figure 1. Flowchart of the study population.

\section{Examined for eligibility \\ for symptoms incidence \\ (Connected to the \\ application in France): \\ $4,126,789$}

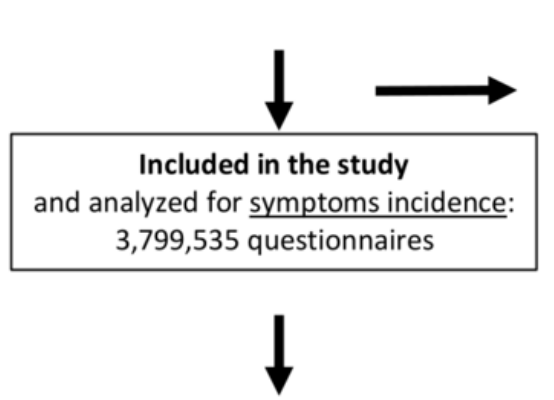

Symptomatic patients assessed for fever and/or cough

(reported from 3/17/2020 to 3/29/2020):

$2,477,174$

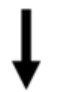

Fever and/or cough positive

Fever 828,952 (33.5\%),

Cough 1,515,557 (61.2\%)
Incomplete questionnaire/

Unknown location: 327,254

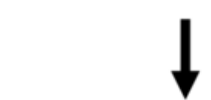

Symptomatic patients assessed for anosmia

(reported from 3/21/2020 to 3/29/2020):

$1,903,741$

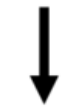

Anosmia positive

325,910 (17.1\%) 
Table 1. Users characteristics.

\begin{tabular}{|c|c|}
\hline Characteristic & Value $\left(n=2,477,174^{a}\right)$ \\
\hline Age (years), average (range), median & 39.12 (15-99), 37 \\
\hline Sex & $-{ }^{b}$ \\
\hline \multicolumn{2}{|l|}{ Body mass index $\left(\mathrm{kg} / \mathrm{m}^{2}\right)$} \\
\hline$\geq 30$ & $436,609(17.6)$ \\
\hline$<30$ & $2,040,555(82.4)$ \\
\hline \multicolumn{2}{|l|}{ Comorbidities } \\
\hline Cardiovascular disease / uncontrolled hypertension & $401,888(16.2)$ \\
\hline Diabetes & $78,354(3.2)$ \\
\hline Malignancy & $72,577(2.9)$ \\
\hline Pulmonary disease & $243,247(9.8)$ \\
\hline Chronic kidney disease & $11,333(0.5)$ \\
\hline Chronic liver disease & $36,677(1.5)$ \\
\hline Pregnancy & $40,766(1.6)$ \\
\hline Immunodepression & $135,624(5.5)$ \\
\hline Immunosuppressive ongoing therapy & $70,927(2.9)$ \\
\hline \multicolumn{2}{|l|}{ Reported symptoms } \\
\hline Fever (body temperature greater $>37.7^{\circ} \mathrm{C}$ ) & $828,952(33.5)$ \\
\hline Cough & $1,515,557(61.2)$ \\
\hline Dyspnea & $658,442(26.6)$ \\
\hline Asthenia & $1,155,297(46.6)$ \\
\hline Complete anorexia & $103,122(4.2)$ \\
\hline Sore throat or muscle aches & $1,837,286(74.1)$ \\
\hline Diarrhea & $497,665(20.1)$ \\
\hline Anosmia or dysgeusia $^{c}$ & $325,910(17.1)$ \\
\hline \multicolumn{2}{|l|}{ Patient triage after questionnaire completion ${ }^{\mathrm{d}}$} \\
\hline No symptoms & $1,322,361(34.8)$ \\
\hline Self-monitoring & $858,878(22.6)$ \\
\hline General practitioner / phone call & $1,033,922(27.2)$ \\
\hline
\end{tabular}

${ }^{\mathrm{a}}$ Symptomatic patient (reported at least one symptom).

${ }^{\mathrm{b}} \mathrm{Sex}$ was not asked to protect the identity of the user.

${ }^{\mathrm{c}}$ Anosmia was reported from March 21, 2020; the number of symptomatic patients during this period was 1,903,741.

${ }^{\mathrm{d}}$ Denominator is $\mathrm{N}=3,799,535$ (all respondents; symptomatic or not). 
Figure 2. Maps displaying the correlation between fever and/or cough and anosmia with hospitalizations for COVID-19. (A) The cumulative number of hospitalized COVID-19-positive patients in France on March 29, 2020. (B) Fever and/or cough reported by users via the application; cumulative amount in French counties from March 17-29, 2020: 3,799,535 respondents (828,952 with fever and 1,515,557 with cough). (C) Anosmia reported by users; cumulative number from March 21-29, 2020: 325,910 positive respondents.

\section{A: Number of hospitalizations for COVID-19}
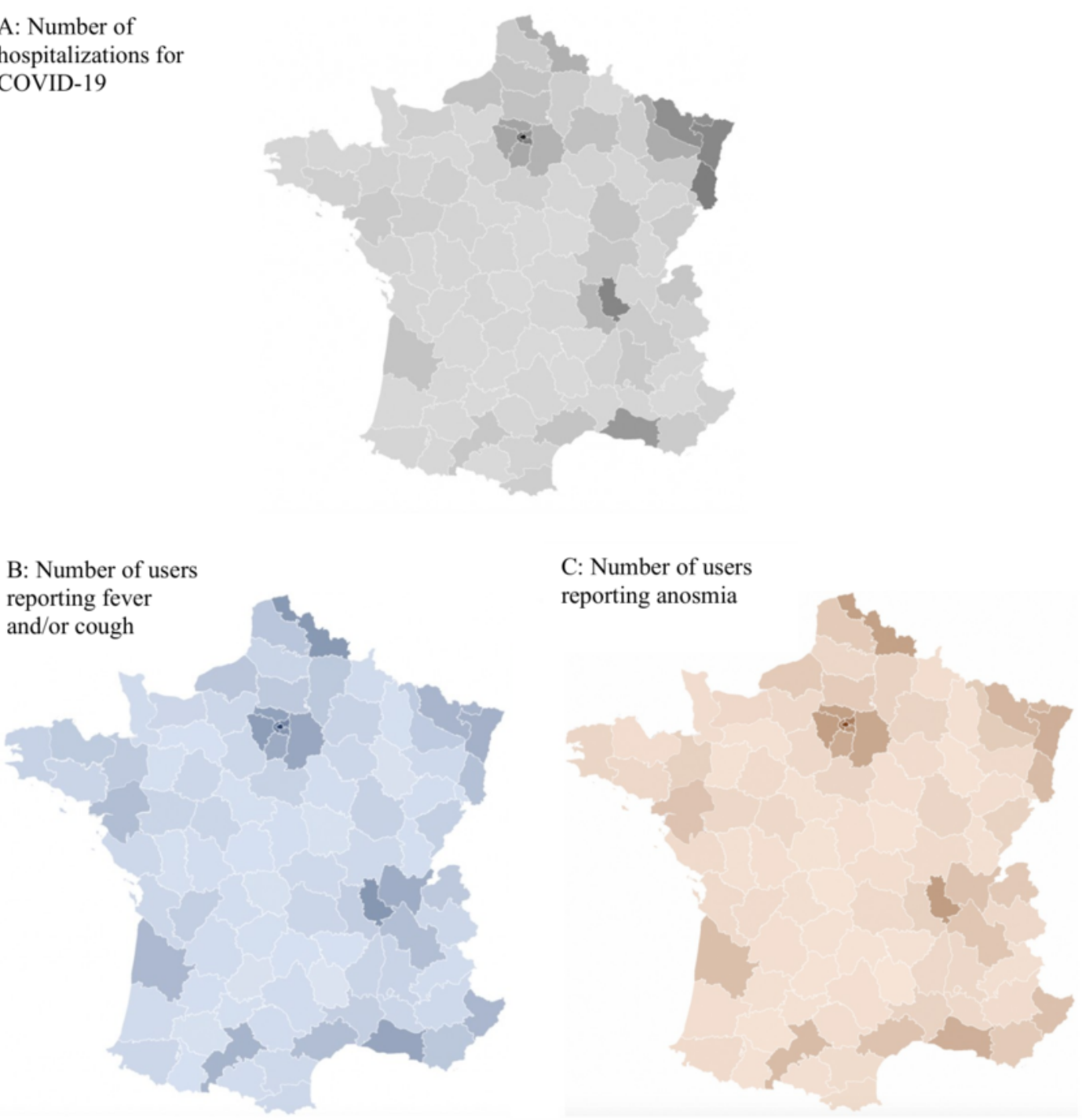

\section{Discussion}

This study suggests that self-reported symptoms of COVID-19 are correlated with COVID-19-related hospitalizations and that anosmia may be strongly associated with COVID-19. This could be explained by a greater specificity compared to other reported symptoms that could result from other respiratory viruses $[7,8]$.
Limitations include lack of medical assessment and virological confirmation of COVID-19 and comparison of application-retrieved data with a distinct set of data from the Ministry of Health reports on hospitalizations. Self-checking application data could be a relevant tool to monitor the dynamics of an outbreak and thus can be a real-time health system response to the epidemic.

\section{Conflicts of Interest}

FD received personal fees from AstraZeneca, Ipsen, Sivan Innovation, Pfizer, Chugai, Takeda, and Roche. All other authors declared no conflicts of interest.

\section{References}

1. Denis F, Basch E, Septans A, Bennouna J, Urban T, Dueck AC, et al. Two-Year Survival Comparing Web-Based Symptom Monitoring vs Routine Surveillance Following Treatment for Lung Cancer. JAMA 2019 Jan 22;321(3):306-307 [FREE Full text] [doi: $\underline{10.1001 / j a m a .2018 .18085}$ ] [Medline: $\underline{\text { 30667494] }}$ 
2. Basch E, Deal AM, Dueck AC, Scher HI, Kris MG, Hudis C, et al. Overall Survival Results of a Trial Assessing Patient-Reported Outcomes for Symptom Monitoring During Routine Cancer Treatment. JAMA 2017 Jul 11;318(2):197-198 [FREE Full text] [doi: 10.1001/jama.2017.7156] [Medline: 28586821]

3. Luo H, Lie Y, Prinzen FW. Surveillance of COVID-19 in the General Population Using an Online Questionnaire: Report From 18,161 Respondents in China. JMIR Public Health Surveill 2020 Apr 27;6(2):e18576 [FREE Full text] [doi: 10.2196/18576] [Medline: $\underline{32319956]}$

4. Guerrisi C, Turbelin C, Blanchon T, Hanslik T, Bonmarin I, Levy-Bruhl D, et al. Participatory Syndromic Surveillance of Influenza in Europe. J Infect Dis 2016 Dec 01;214(suppl_4):S386-S392. [doi: 10.1093/infdis/jiw280] [Medline: 28830105]

5. maladiecoronavirus.fr. 2020. URL: https://maladiecoronavirus.fr/ [accessed 2020-03-17]

6. Guan W, Ni Z, Hu Y, Liang W, Ou C, He J, China Medical Treatment Expert Group for Covid-19. Clinical Characteristics of Coronavirus Disease 2019 in China. N Engl J Med 2020 Apr 30;382(18):1708-1720 [FREE Full text] [doi:

10.1056/NEJMoa2002032] [Medline: $\underline{32109013}$ ]

7. Menni C, Valdes AM, Freidin MB, Sudre CH, Nguyen LH, Drew DA, et al. Real-time tracking of self-reported symptoms to predict potential COVID-19. Nat Med 2020 May 11. [doi: 10.1038/s41591-020-0916-2] [Medline: 32393804]

8. Bénézit F, Le Turnier P, Declerck C, Paillé C, Revest M, Dubée V, et al. Utility of hyposmia and hypogeusia for the diagnosis of COVID-19. The Lancet Infectious Diseases 2020 Apr 15 [FREE Full text] [doi: 10.1016/S1473-3099(20)30297-8] [Medline: 32304632]

\section{Abbreviations \\ COVID-19: coronavirus disease \\ GP: general practitioner}

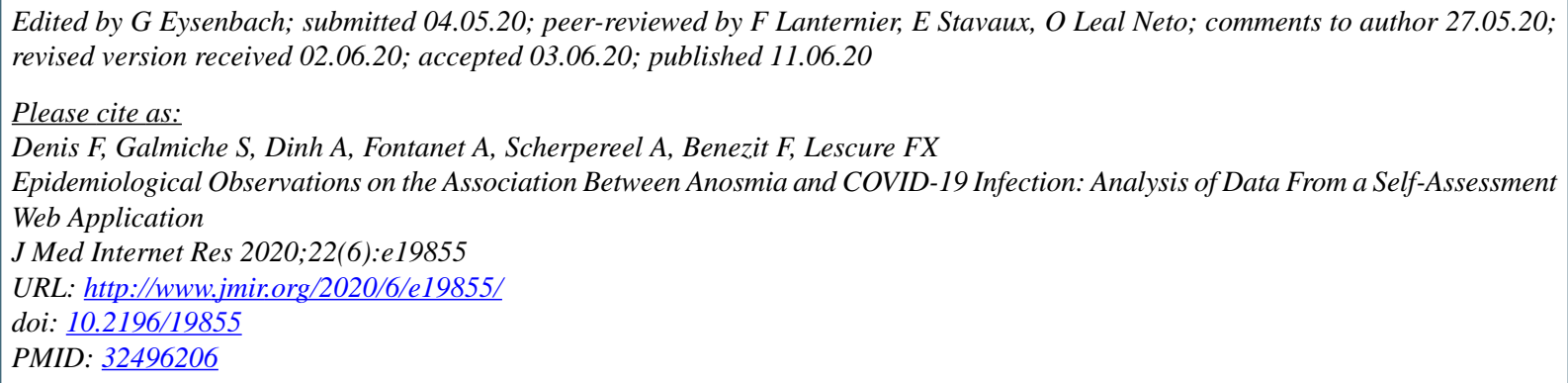

CFabrice Denis, Simon Galmiche, Aurélien Dinh, Arnaud Fontanet, Arnaud Scherpereel, Francois Benezit, François-Xavier Lescure. Originally published in the Journal of Medical Internet Research (http://www.jmir.org), 11.06.2020. This is an open-access article distributed under the terms of the Creative Commons Attribution License (https://creativecommons.org/licenses/by/4.0/), which permits unrestricted use, distribution, and reproduction in any medium, provided the original work, first published in the Journal of Medical Internet Research, is properly cited. The complete bibliographic information, a link to the original publication on http://www.jmir.org/, as well as this copyright and license information must be included. 